\title{
The Effects of Three Different Background Music between Vocal, Instrumental and Silent on Verbal and Spatial Task Performance in Learning
}

Norazirah binti Buang, ${ }^{(1)}$ Amalina Ulya, ${ }^{(2)}$ Sousan Naseri ${ }^{(3)}$

Universiti Putra Malaysia ${ }^{(1)(2)(3)}$

DOI : 10.23917/varidika.v31vi2i.10224

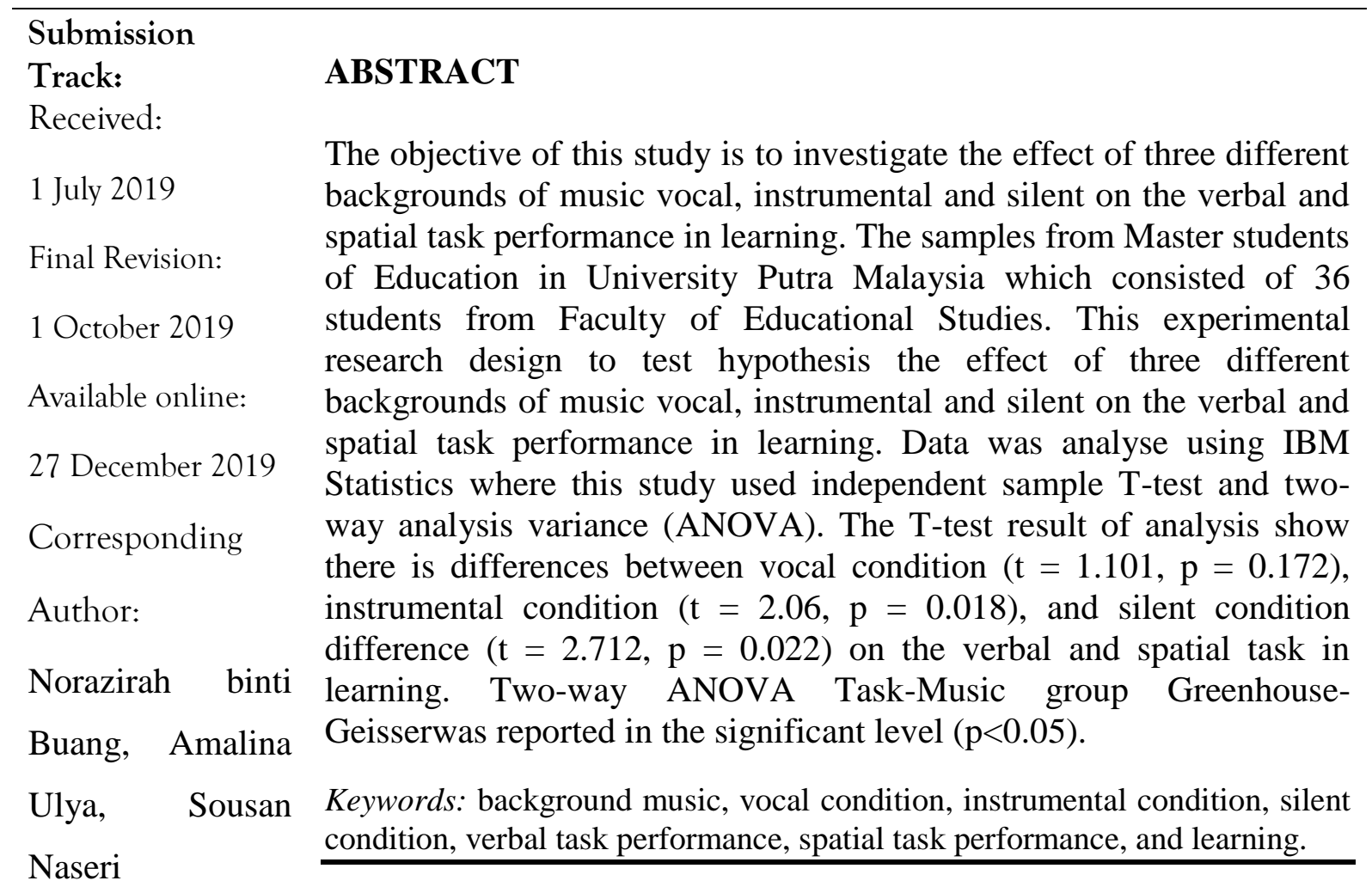

\section{INTRODUCTION}

The advancement of technology, portable audio devices has led people to tend to listen to music more often music is important in the life of someone in doing activities such as working, driving, cooking and learning. Neurological studies show that human brains are born with music (Demorest \& Morrison, 2000). According to Mammarella, Fairfield and Cornoldi (2007), they considered white noise as a unique type of sound. It is because it consists each of the frequency outside the range of the human hearing and has been used in relaxation technique. According to Dalton and Behm (2007), music background consists a rhythm, melody and harmony sound that has been reported annoying because the sound is known as auditory signals unwanted or interference on human performance. 
The different background of music can affect a person's cognitive performance in doing the task. In early 1990, Rausher, Shaw and Ky (1993) study about the effects of Mozart' music show that the music can enhance spatial task performance in silence condition. According to Perham and Vizard (2011) in his study shows that music can affect cognitive tasks such as reading comprehension with music because of the presence of simultaneous conflicts in semantic information processing task focus and sound irrelevant. Not only that, according to Perham and Vizard (2011) in his study show background music can affect learning, memory and working memory. Studies by Alley \& Greene (2008); Cassidy \& MacDonald (2007); Avila, Furnham, \& McClelland, (2011); Jancke\&Sandmann (2010)also show background music can affect learning, memory and working memory and attention to the task of monitoring the cognitive.

In learning students have a tendency going better in reduce stress, be quiet, be happily and more creative in the existence of a suitable background music in their learning(Chie, Qiu Ting, Karthigeyan \& Kartpagam, 2009). This study showed that the performance can be improved by the use of an effective music and not to stimulate them. According to Kotsopoulou and Hallam (2004), many students tend to listen to music while studying. In a study conducted by Oldham, Cummings, Mischel, Schmidthe and Zhan (1995) and same reported by Furnham \& Bradley (1997) shows people prefer to do their work with music as the situation calm and have a major impact on work performance, assessment of fatigue and satisfaction in an organisation. However, according to Perham and Vizard (2011) showed that listening to music while working disturb them because they think like listening to someone speak. In addition, hearing music also helped generate a strong feeling of knowing regarding the past.

According to Alley and Greene (2008), amodel of working memory (WM-Working Memory) developed by Baddeley and Hitch (1974) was an attempt to mimic the processes employed in short-term memory (STM) to long-term memory (LTM ) can be. Where there are active memories as opposed to inactive memory. Active memory (active memory) is not only referred to the processing of events that are happening but also activities and calculations based on information derived from long-term memory.

\section{RESEARCH METHOD}

\subsection{Participants}

Participants in this study were 36 postgraduate educational studies students, 3 is male and 35 is female from a public research university in Malaysia.

\section{$2.2 \quad$ Instruments}

In this experiment, verbal and spatial has been used to collect data. As for verbal tasks, the participant was given Reading Comprehension Task, Word Memory Task, and Similarities Task, and for the spatial task, the set of Mental Rotation Task, Paper Folding Task, and Object Location Task were given. Word Memory Task and Object Location where presented using Microsoft PowerPoint in ten seconds. The instrumental music (piano) by from Fabrizio Caligaris - "Somewhere over the Rainbow" and vocal music use by Mike Tomkins- "We are Young”.

\subsection{Procedures}


The participants were randomly given a set of the test provided, whether it is spatial task set and verbal task set, which need to be completed. Before the experiment, the participant received a consent form which needs to be confirmed as their participation in this study. There was a brief on the study as they volunteer to participate and the well explained on how the study was conducted and particular task that needs to complete the experiment.

\section{$2.4 \quad$ Pilot Test}

A pilot test as to ensure the validity and reliability of the study were carried out among six participants. The pilot test was conduct similarly with the real methods and receives the same set of the task with certain music condition.

\subsection{Data analysis procedure}

The computation of collected data used the Statistical Package for Social Science (SPSS). The inferential statistics that computer in this experimental study using independent sample T-test to compare the mean between groups and Two-Way Analysis of Variance (ANOVA) has used to compare three or more group in this study.

\section{RESULTS \& DISCUSSION}

The discussion is written to interpret and describe the significance of your findings in light of what was already known about the issues being investigated, and to explain any new understanding or insights about the problem after you have taken the findings into consideration. It should connect to the introduction by way of the research questions or hypotheses you posed and the literature you reviewed, but it does not simply repeat or rearrange the introduction; this section should always explain how your study has moved the reader's understanding of the research problem forward from where you left them at the end of the introduction.

\subsection{Verbal and spatial task performance under instrumental music condition}

Table 1 shows the result of verbal and spatial task performance under instrumental condition. Hypothesis 1 shows that there is no significant difference between the verbal and spatial task performance under instrumental music condition. The hypothesis is rejected. The results show the task performance under instrumental music condition between verbal and spatial are statistically difference $(\mathrm{t}=2.06, p=0.018)$, which spatial task performance is better than verbal task performance under instrumental music condition.

Table 1:T-Test Results of Verbal and Spatial Task Performance under Instrumental Condition

\begin{tabular}{lllllll}
\hline \multirow{2}{*}{ Instrumental } & Task & $\mathbf{n}$ & Mean & $\begin{array}{l}\text { Std. } \\
\text { Deviation }\end{array}$ & t-stats & p-value \\
\cline { 2 - 7 } & Verbal & 6 & 51.1900 & 2.91489 & 2.06 & 0.018
\end{tabular}




$$
\begin{array}{llll}
\text { Spatial } & 6 & 62.7483 & 13.36864
\end{array}
$$

Note: $p<0.05$

\subsection{Verbal and spatial task performance under vocal music condition}

Table 2 shows the result of verbal and spatial task performance under vocal condition. Hypothesis 2 shows that there is no significant difference between verbal and spatial task performance under vocal music condition. The hypothesis is accepted. The results show the task performance under vocal music condition between verbal and spatial are no statistically difference $(\mathrm{t}=1.101, p=0.172)$, which spatial task performance just slightly higher than verbal task performance under vocal music condition. The results indicate that vocal music conditions do not impact on verbal or spatial task performance.

Table 2:T-TestResults of Verbal and Spatial Task Performance under Vocal Condition

\begin{tabular}{lllllll}
\hline \multirow{2}{*}{ Vocal } & Task & n & Mean & $\begin{array}{l}\text { Std. } \\
\text { Deviation }\end{array}$ & t-stats & p-value \\
\cline { 2 - 6 } & Verbal & 6 & 48.2150 & 6.67886 & 1.101 & 0.172 \\
& Spatial & 6 & 53.9183 & 10.79072 & & \\
\hline
\end{tabular}

Note: $p<0.05$

\subsection{Verbal and spatial task performance under silence condition.}

Table 3 shows the result of verbal and spatial task performance under silent condition. Hypothesis 3 shows that there is no significant difference between verbal and spatial task performance under silent condition. The hypothesis is rejected. The results show the task performance under silent condition between verbal and spatial are statistically difference $(\mathrm{t}=$ $2.712, p=0.022$ ), which spatial task performance is better than verbal task performance under instrumental music condition.

Table 3: T-Test Result of Verbal and Spatial Task Performance under Silent Condition

\begin{tabular}{lllllll}
\hline \multirow{3}{*}{ Silent } & Task & n & Mean & Std. Deviation & t-stats & p-value \\
\cline { 2 - 7 } & Verbal & 6 & 48.8100 & 6.67886 & 2.712 & $\mathbf{0 . 0 2 2}$ \\
& Spatial & 6 & 59.8017 & 8.03483 & & \\
\hline
\end{tabular}

Note: $p<0.05$

\subsection{Analysis of Two-Way repeated ANOVA}

The final data analysis is using Two-Way Repeated ANOVA to find is there any significant difference between this study groups means as determined by two-way ANOVA. In this study the significant level $(p<0.05)$ was reported for Task Group and Music group for item Music (within the group). As ANOVA results, there is the difference between this study groups 
means but only music group was reported to the significant level $(p<0.05)$. Therefore, there is a significant effect of the music background at the $p<0.05$ level in the 3-Music condition.

Table 4: Two-way ANOVA

\begin{tabular}{|c|c|c|c|c|c|c|}
\hline Source & & $\begin{array}{l}\text { Type III Sum Of } \\
\text { Squares }\end{array}$ & Df & $\begin{array}{l}\text { Mean } \\
\text { Square }\end{array}$ & $\mathbf{F}$ & Sig. \\
\hline Task & Sphericity Assumed & 209.7 & 2 & 104.85 & 1.179 & 0.347 \\
\hline \multirow[t]{3}{*}{ (Within Group) } & Greenhouse-Geisser & 209.7 & 1.501 & 139.673 & 1.179 & 0.341 \\
\hline & Huynh-Feldt & 209.7 & 2 & 104.85 & 1.179 & 0.347 \\
\hline & Lower-Bound & 209.7 & 1 & 209.7 & 1.179 & 0.327 \\
\hline Task & Sphericity Assumed & 889.642 & 10 & 88.964 & & \\
\hline \multirow[t]{3}{*}{ (Between Group) } & Greenhouse-Geisser & 889.642 & 7.507 & 118.511 & & \\
\hline & Huynh-Feldt & 889.642 & 10 & 88.964 & & \\
\hline & Lower-Bound & 889.642 & 5 & 177.928 & & \\
\hline Music & Sphericity Assumed & 798.251 & 1 & 798.251 & 17.281 & 0.009 \\
\hline \multirow[t]{3}{*}{ (Within Group) } & Greenhouse-Geisser & 798.251 & 1 & 798.251 & 17.281 & 0.009 \\
\hline & Huynh-Feldt & 798.251 & 1 & 798.251 & 17.281 & 0.009 \\
\hline & Lower-Bound & 798.251 & 1 & 798.251 & 17.281 & 0.009 \\
\hline Music & Sphericity Assumed & 230.956 & 5 & 46.191 & & \\
\hline \multirow[t]{3}{*}{ (Between Group) } & Greenhouse-Geisser & 230.956 & 5 & 46.191 & & \\
\hline & Huynh-Feldt & 230.956 & 5 & 46.191 & & \\
\hline & Lower-Bound & 230.956 & 5 & 46.191 & & \\
\hline Task * Music & Sphericity Assumed & 62.569 & 2 & 31.284 & 0.333 & 0.724 \\
\hline \multirow[t]{3}{*}{ (Whit In Group) } & Greenhouse-Geisser & 62.569 & 1.77 & 35.351 & 0.333 & 0.7 \\
\hline & Huynh-Feldt & 62.569 & 2 & 31.284 & 0.333 & 0.724 \\
\hline & Lower-Bound & 62.569 & 1 & 62.569 & 0.333 & 0.589 \\
\hline (Task*Music) & Sphericity Assumed & 938.504 & 10 & 93.85 & & \\
\hline \multirow[t]{3}{*}{ (Between Group) } & Greenhouse-Geisser & 938.504 & 8.85 & 106.051 & & \\
\hline & Huynh-Feldt & 938.504 & 10 & 93.85 & & \\
\hline & Lower-Bound & 938.504 & 5 & 187.701 & & \\
\hline
\end{tabular}




\section{Discussion}

As conclusion according to the results of this study that was reported, there are significant differences between verbal and spatial task performance under instrumental music condition while this study claims that there is no significant difference between verbal and spatial task performance under vocal music condition. This research result is same from the previous study where there is no significant difference between verbal and spatial task performance under vocal music condition. The study conducted by Alley and Greene (2008) on using 4 digit task with different background auditory stimuli such as instrumental music; the irrelevant speech; and the silence part. The digit task showed the better result in silence condition rather than speech condition. Alley and Greens (2008) study also contributed the difference among vocal music and speech music condition. The vocal music condition has the little distracting rather than speech condition. The results of this study did not show the significant difference between the experimental groups that were examined in the same condition.

Personality type also is one of the variables that affect on individual task performance. Avila, Furnhamand McClelland (2011) mentioned introverts (low extroversion) and extroverts (high extroversion) are different in individual's cortical arousal levels which are known as performing the great potential without distractions. In detail, extroverts related to higher arousal threshold level tend to seek arousal or stimulating situations. Therefore, Campbell \& Hawley (1982) predicted detrimental effects of music on task performance. In this case, when music had been introduced, extravert's personality type may show the better performance rather than introverts. In the year 1997, Furnham \& Bradley (1997) study on radio distraction level and radio extracts on recall memory and reading tasks (comprehension) in 10-Extravert and 10-Introvert individuals. The results of this experiment showed asignificant difference between the extrovert and introvert group. Extravert performance was much better in memory recall task. As general the introverts showed the weak performance in another task as well.

Besides, studies also find that there is a significant difference between verbal and spatial task performance under silent condition. Finally, this study reported the difference between means of music conditions in spatial task performance among respondents. The overall results show instrumental music condition is better for both verbal and spatial task performance. The previous study by Furnham \& Bradley (1997)showsone of the factor effects on the result obtain is the different type of background music. In addition O'Hare (2011) and Furham \& Bradley (1997) mentioned about the positive effect of instrument music on memory recalled which is showed that vocal condition is in the line with poor performance. However, the results of Kotsopoulou \& Hallam (2004) mentioned, a study on the music condition did not show any effect on memory and recalled task.

This study contributed that may background music can affect on learning, memory and working memory.The music condition may reduce stress, tend respondents to be quiet and make them happier and more confidence. In addition, these conditions may make them show better performance. This study results are similar to the previous study (Perham \&Vizard, 2011; Avila, Furnham \& McClelland, 2011; Cassidy \& MacDonald, 2007; Alley \& Greene, 2008) results for instrumental music conditions and vocal music condition. These findings provide valuable alternatives for the students especially, to achieve more or less in completing their task. 


\section{CONCLUSION}

The study conducted randomly towards the students without considering their strength in verbal or spatial intelligence. Additionally, this study only focused on three background music; silent, instrumental and vocal. It is also possible that each individual may have their personal preferences music.

\section{REFERENCES}

Alley, T. R., \&Greene, M. E. (2008).The Relative and Perceived Impact of Irrelevant Speech, Vocal Music and Non-vocal Music on Working Memory. CurrPsychol27,277-289.

Avila, C., Furnham, A., \& McClelland, A. (2011).The Influence of Distracting Familiar Vocal Music on Cognitive Performance of Introverts and Extraverts. Psychology of Music, 40(1), 84-93

Baddeley, A. D., \& Hitch, G. (1974). Working memory. In G.H. Bower (Ed.), The psychology of learning and motivation: Advances in research and theory (Vol. 8, pp. 47-89). New York: Academic Press.

Campbell, J. \& Hawley, C. (1982). Study habits and Eysenck's theory of extraversion introversion. Journal of Research in Personality, 16, 139-146.

Cassidy, G., \& Macdonald, R. A. R. (2007). The Effect of Background Music and Background Noise on The Task Performance of Introverts and Extraverts. Psychology of Music,35(3), 517-537

Chie, Qiu Ting, Karthigeyan \& Kartpagam, K. (2009). The effects of music tempo on memory performance using maintenance rehearsal and imagery. Sunway Academic Journal, 6, 114-132.

Dalton, B. H. \& Behm, D. G. (2007). Effects of noise and music on human and task performance: A systematic review. Occupational Ergonomics IOS Press, 7, 143-152

Demorest, S. M., \& Morrison, S. J. (2000). Does Music Make You Smarter? Music Educators Journal, 8(2), 33-39.

Furnham, A., \& Bradley, A. (1997). Music While YouWork: The Differential Distraction of Background Music on the Cognitive Test Performance of Introverts and Extraverts. Applied Cognitive Psychology, 11, 445-455.

Jäncke, L., \&Sandmann, P. (2010). Music listening while you learn: No influence of background music on verbal learning. Behavioural and Brain Functions, 6(3), 1-14.

Kotsopoulou, A., \&Hallam, S. (2004). Cross-Cultural Differences in Listening To Music While Studying. Music Perception and Cognition. 397-400 
Mammarella, N., Fairfield, B., \&Cornoldi, C. (2007). Does Music Enhance Cognitive Performance in Healthy Older Adults? The Vivaldi Effect. Ageing Clinical and Experimental Research, 19(5), 1-6.

Oldham, G., Cummings, A., Mischel, L., Schmidthe, J. \& Zhan, J. (1995). Listen while you work? Quasi-experimental relations between personal-stereo headset use and employee work responses. Journal of Applied Psychology, 80, 547-564.

O'Hare, A. (2011). The Effect of Vocal and Instrumental Background Music on Primary School Pupils' Verbal Memory Using A Sentence Recall Task. Student Psychology Journal, 2.

Perham, N., \&Vizard, J. (2011). Can Preference for Background Music Mediate the Irrelevant Sound Effect?.Applied Cognitive Psychology, 25, 625-631.

Rauscher, F.H., Shaw, G.L. and Ky, K.N. (1993). Music and Spatial Task Performance. Nature, 365, 611.

Bogdonoff, S., \& Rubin, J. (2007). The regional greenhouse gas initiative: Taking action in Maine. Environment, 49(2), 9-16.

Mora, C., \& Maya, M. F. (2006).Effect of the rate of temperature increase of the dynamic method on the heat tolerance of fishes.Journal of Thermal Biology, 31, 337-341. doi: 10.101b/jtherbio.2006.01.055

United States Environmental Protection Agency. (2007, May 4). Climate Change.Retrieved From the Environmental Protection Agency website: http://www.epa.gov/climatechange

Gelspan, R. (2007). The Heat Is Online. Lake Oswego, OR: Green House Network. Retrieved fromThe Heat Is Online website: http://www.heatisonline.org 